\title{
THE ORIENTATION OF MIGRANT AND NON-MIGRANT MONARCH BUTTERFLIES, DANAUS PLEXIPPUS (L.)
}

\author{
BY JAMES E. KANZ* \\ Department of Biology \\ Tufts University \\ Medford, Massachusetts 02155
}

\section{INTRODUCTION}

Many species of butterflies migrate (Nielsen and Nielsen, 1952; Tilden, 1962; Williams, 1951, 1958). The fall southward migration of the North American Monarch butterfly, Danaus plexippus L., is a classic example of long-distance insect migration (Urquhart, 1960, 1976; Walker, 1914; Williams, Cockbill, Gibbs, and Downes, 1942). Evidence from tagging studies indicates that the same butterflies traveling south in the fall return northward the following spring (Urquhart, personal communication). It is unlikely, however, that fall migrants from the northern latitudes $\left(48^{\circ} \mathrm{N}\right)$ return as far north in the spring.

Johnson (1969), Urquhart (1960), Williams et al. (1942), and Williams (1958) have provided descriptive information on several aspects of $D$. plexippus migration. However, little experimental work exists on the isolation of environmental orientation cues and their role in the seasonal movements of the Monarch. Baker (1968a) hypothesized an evolutionary scheme for the development of sunorientation in a butterfly's search for new habitats. Using field data on general flight directions of migrating European butterflies, Baker $(1968 \mathrm{a}, \mathrm{b})$ determined that sun orientation was apparently used by Pieris rapae, P. brassicae, P. napi, Maniola jurtina, Aglis urticae, and Inachis io during their migrations. This paper reports which environmental orientation cues are used by caged migrant and nonmigrant Monarchs, and suggests how such cues are used.

\footnotetext{
*Present address: Marine Biomedical Institute, University of Texas Medical Branch, 200 University Boulevard, Galveston, Texas 77550.

Manuscript received by the editor August 20, 1977.
} 


\section{MATERIALS AND METHODS}

Experiments used laboratory-reared and "wild-caught" Monarch butterflies ( $D$. plexippus $\mathrm{L}$.) of both sexes. The laboratory colony was reared from the egg under mid-summer conditions: $24^{\circ} \mathrm{C}$ under a 15:9 hour light/dark schedule (Kanz, 1973; Urquhart and Stegner, 1966). Some laboratory-reared Monarchs were reared under a photoperiod advanced 6 hours. Predominantly laboratory-reared animals were used for summer experiments. Wild-caught migrants were used in fall tests. Fall migrants were maintained in the field in frame cages $(3 \times 3 \times 21 / 2 \mathrm{~m})$ covered with nylon netting and placed over patches of golden rod and asters.

Summer experiments with non-migrants were conducted in an open field in Lexington, Massachusetts. Studies with fall migrants were conducted at the Eastern Point Audubon Sanctuary in Gloucester, Massachusetts. Eastern Standard Time (EST) was used for summer and fall experiments.

Experimental orientation cages were circular $(80 \mathrm{~cm}$ diameter $)$ and mounted on a rotatable base. The floor of the cages was marked off into $45^{\circ}$ sectors. The periphery $(20 \mathrm{~cm}$ height $)$ and top were wire screening. Entrance was through a door in the top. Two types of orientation cages were used: (1) transparent-periphery cages with both terrestrial and celestrial cues visible and (2) opaqueperiphery cages with a beige strip of no-glare cloth around the periphery so only celestial cues were visible.

Experiments were conducted under sky conditions ranging from clear to overcast. Orientation cages were placed in the center of a field so that terrestrial cues were symmetrical about the cages. Terrestrial cues were distant enough so as not to be visible to animals in opaque-periphery cages. Cages were oriented to true north and the cages could be rotated to any desired azimuth.

Male or female Monarch butterflies $(\mathrm{N}=10-20)$ were released into an orientation cage, and data collection started 15 min later. Cage positions of the Monarchs were monitored at intervals ranging from 1 to $15 \mathrm{~min}$ and positions were scored on circular data sheets divided into $45^{\circ}$ sectors. Each animal's position in relation to true north could be designated within $\pm 5^{\circ}$. With few exceptions, the cage position recorded for each animal was a resting position (i.e., the butterfly was not in flight). Following each reading, the cage was usually rotated. The side of the cage from which the 
observations were made was randomized, but always excluded those sides directly toward and away from the sun. The presence of the experimenter during a reading (an elapsed time of 10-30 sec) did not appear to affect the butterflies' positions. Unless otherwise noted, animals were used for only one experiment and then released with vanishing azimuths recorded; males or females were used in a particular experiment.

The butterflies' orientation cage positions were converted to azimuths with a protractor. These orientation azimuths were then treated as a circular distribution and the following parameters obtained for each observation time (Batschelet, 1965; Greenwood and Durand, 1955): (1) mean orientation direction $(\theta)$; (2) a grouping factor ( $r$ ) indicating the extent to which the butterfly azimuths for an observation were concentrated about the $\theta$ for that observation; (3) an angular deviation (AD) for $\theta$; and (4) the probability $(P)$ of $\mathrm{r}$ occurring by chance. Computer plots were made for $\theta$ and the sun azimuth values as a function of time of day. The orientation response of the Monarchs was considered significant when the $P$ for a distribution of animals (in the orientation cages or vanishing azimuths) was $\leqslant 0.05$.

Other data recorded at each reading included: (1) time of day; (2) temperature; (3) humidity; (4) surface wind velocity (with a Taylor 3105 anemometer) and direction; (5) sun azimuth and altitude computed from a Nautical Almanac and Tables of Computed Altitude and Azimuth for the appropriate latitude. Ambient temperature for the fall tests $\left(10^{\circ}-18^{\circ} \mathrm{C}\right)$ was lower than for summer $\left(18^{\circ}-32^{\circ} \mathrm{C}\right)$ experiments. When ambient temperatures fell below $16^{\circ} \mathrm{C}$, the butterflies displayed sunning behavior: turning away from the sun and spreading the wings in order to increase surface area exposed to sun and thus body temperature (Kanz, 1973; Urquhart, 1960). Sunning is often accompanied by shivering (Kammer, 1968, 1970; Urquhart, 1960), and was only seen in fall migrants. Sunning Monarchs were indicated on the data sheets and in subsequent analyses, computation of $\theta, \mathrm{AD}, \mathrm{r}$ and $P$ with and without sunning Monarchs were made.

\section{RESULTS}

Field Behavior of Migrant and Non-Migrant Monarch Butterflies Non-migrant summer Monarchs left their overnight roosting trees 
as soon as ambient temperatures permitted flight (approximately $13^{\circ} \mathrm{C}$ ) and engaged in feeding and mating throughout the day until sunset.

Fall migrating Monarchs passing through Gloucester, Massachusetts, frequently remained in the area for several days, depending upon weather conditions. Fall migrants left overnight roosting trees to feed (except when it rained) when ambient temperatures exceeded $10^{\circ}-12^{\circ} \mathrm{C}$ (Kanz, 1973); mating occurred infrequently. At approximately $1600 \mathrm{hrs}$ (EST) the butterflies returned to their roosting trees. This cycle was repeated each day until migration resumed. Fall migratory flights occurred between 1000 and 1400 hrs, EST (Brower, personal communication; Urquhart, personal comminication). Fall migratory flight occurred with north, northeast, or northwest winds.

\section{Butterfly Orientation in Opaque Periphery Cages}

Laboratory-reared, non-migrants oriented toward the sun's azimuth throughout the day when the sun was the only environmental cue available (Fig. 1). To examine the possibility that this orientation was actually a shade-seeking response (i.e., orienting to the shaded area of the cage and thus the side toward the sun) a sunshade was positioned so that a shadow was cast over the half of the orientation cage facing the sun. If butterflies were seeking shade, their cage positions should fall within the shaded area of the cage. If Monarchs were sun-orienting, the butterflies would move toward the sun's azimuth, stopping as they entered the shaded portion of the cage and their cage positions would fall along the shade line cast by the sun-shade. For such an experiment, 59\% of the butterflies' cage positions were within $\pm 5 \mathrm{~cm}$ of the shade line; and $72 \%$ of the cage positions were on the lid. Therefore, sunward orientation of caged, summer, non-migrants seemed to be an orientation to the sun and not an attempt to seek shade.

Without celestial or terrestrial cues (overcast day), laboratoryreared, summer, non-migrants displayed a random orientation pattern (Fig. 2). With the sun visible, the mean absolute difference between a given $\theta$ and the sun's azimuth for that $\theta$ (i.e., $\mid \theta$-sun azimuth $\mid$ ) was $23^{\circ}$ for opaque periphery cage, laboratory-reared, non-migrants, and $99^{\circ}$ without the sun visible (Table I). Seventythree percent of the sun-visible readings, versus $2 \%$ of the no-sun readings, showed significantly different Monarch cage distributions 


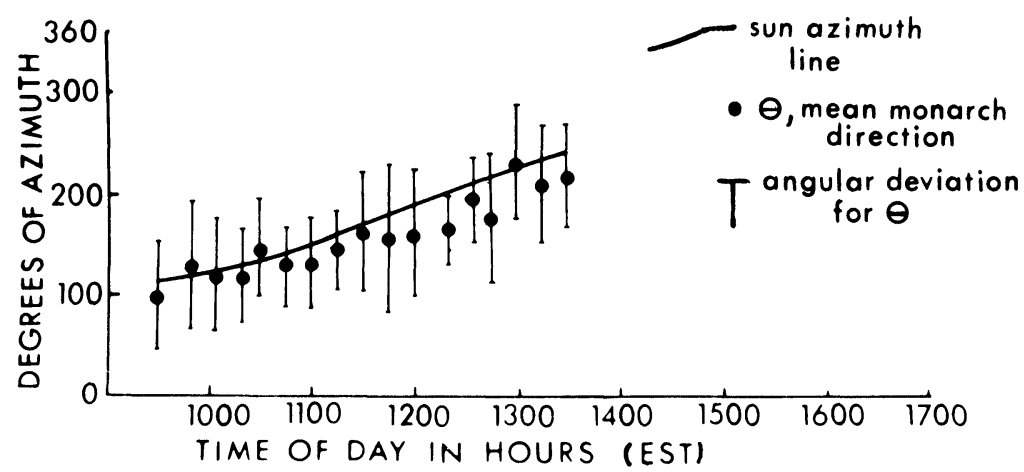

Fig. 1. Orientation of laboratory-reared, summer, non-migrants in an opaque periphery cage on a clear day. $\theta$ 's lie close to the sun azimuth line throughout the course of the test.

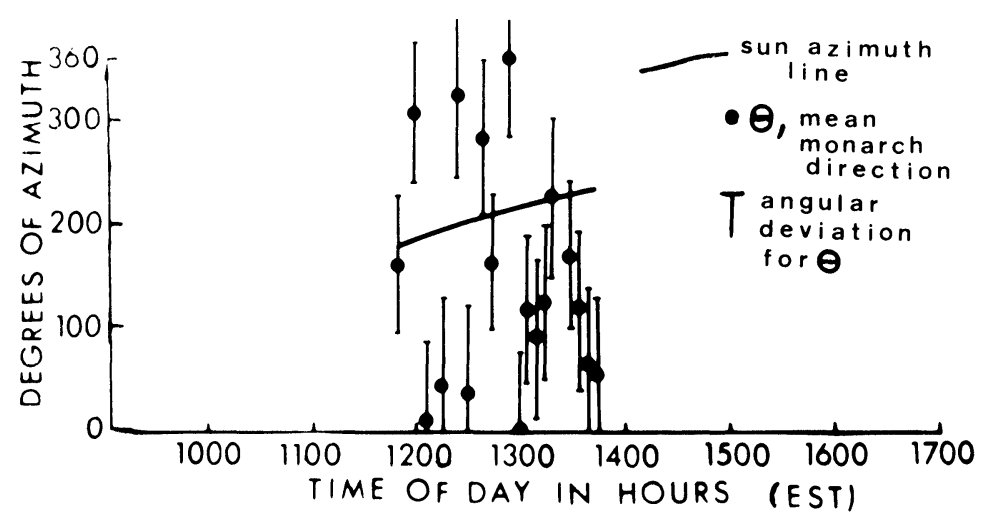

Fig. 2. Random mean orientation of summer, laboratory-reared monarchs in opaque periphery cages on an overcast day.

(Raleigh Test, $P \leqslant .05$ ). Thus, caged non-migrant Monarchs responded to the sun as an orientation cue. Two tests under sunvisible and no-sun-visible conditions using wild-caught summer, non-migrants, paralleled the results with laboratory-reared animals: wild-caught non-migrants, sun-oriented on clear days but oriented randomly on overcast days. However, if summer Monarch followed the azimuth of the sun, their daily movement would be to the south. Such a movement is inconsistent with the random wandering observed for summer non-migrants (Urquhart, 1960). Therefore, the sun orientation of summer non-migrant Monarchs in opaque cages 
with the sun visible may have been an escape reaction (see Discussion).

Fall migrants in opaque periphery cages also displayed a sun orientation when the sun was visible (Fig. 3): mean $\mid \theta$-sun azimuth| $=39^{\circ}, 31 \%$ of the readings showing significant Monarch concentrations about the mean orientation direction (Table I). Low ambient temperatures during fall tests $\left(10^{\circ}-18^{\circ} \mathrm{C}\right)$ compared to summer tests $\left(18^{\circ}-32^{\circ} \mathrm{C}\right)$ might be one reason for the difference in sun-orienting response between the two populations. However, the data suggest that caged fall migrants sun-orient when the sun is their sole orientation cue. Sun orientation would result in fall migrants moving south, the direction Monarch butterflies take during their fall migration. A distinction can be seen between the sun orientation of fall migrants and summer non-migrants in opaque periphery cages: the mean $\mid \theta$-sun azimuth $\mid$ value for fall migrants was not as consistent throughout the day as it was for nonmigrants. Caged fall migrants showed a mean orientation direction closer to the sun's azimuth (mean $\mid \theta$-sun azimuth $\mid=31^{\circ}$ ) from 1000 to $1400 \mathrm{hrs}$ (EST) than before or after this time period (mean $\mid \theta$-sun azimuth $\mid=44^{\circ}$ and $52^{\circ}$, respectively). The $1000-1400 \mathrm{hrs}$ time period corresponds to the migratory period of fall migrants (Brower, personal communication; Kanz, 1973; Urquhart, personal communication; Kanz, 1973; Urquhart, personal communication). The sun-orienting response of non-migrants on the other hand, was consistent, or even improved, throughout the course of the day $\left(30^{\circ}, 27^{\circ}\right.$, and $12^{\circ}$, respectively for prior to $1000 \mathrm{hrs}, 1000-1400$ $\mathrm{hrs}$ and after $1400 \mathrm{hrs})$. This suggests that there is more to the sun orientation of fall migrants than a sun-orienting escape response.

The wider divergence of $\theta$ 's from the sun's azimuth in the fall tests cannot wholly be ascribed to cooler autumn temperatures in the morning and late afternoon hours. Two fall experiments, including that illustrated in Fig. 3, were conducted when ambient temperatures ranged from $13^{\circ}$ to $16^{\circ} \mathrm{C}$. This temperature range was less than or equal to that recorded for the time period 1000 $1400 \mathrm{hrs}$ for all but two of the remaining fifteen tests of this series (i.e., fall migrants in opaque periphery cages with the sun visible). Caged migrants from these two tests still showed a mean orientation closer to that of the sun's azimuth during the observed 1000 $1400 \mathrm{hr}$ migratory period. The orientation of caged fall migrants was random on overcast days (Table I). 


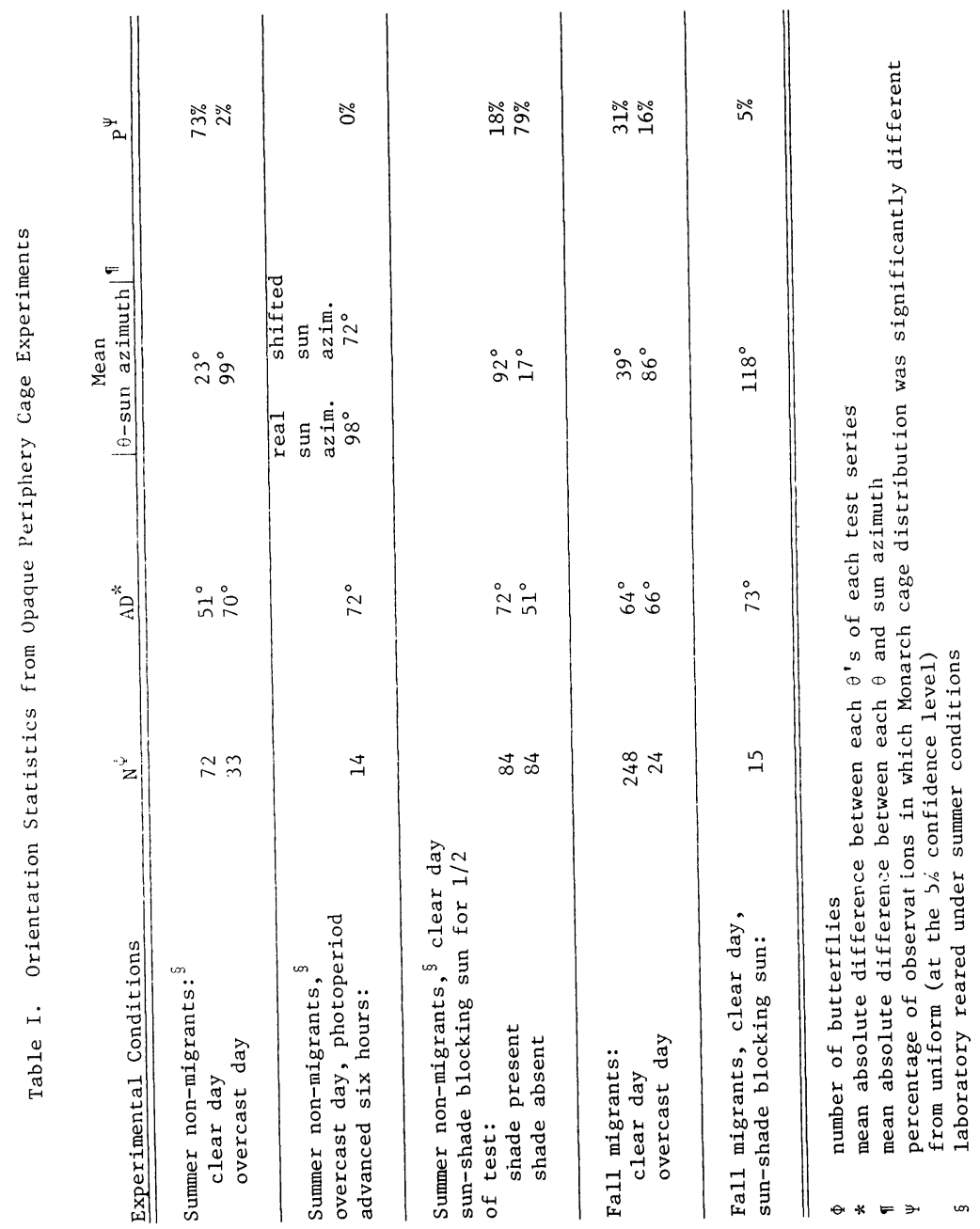




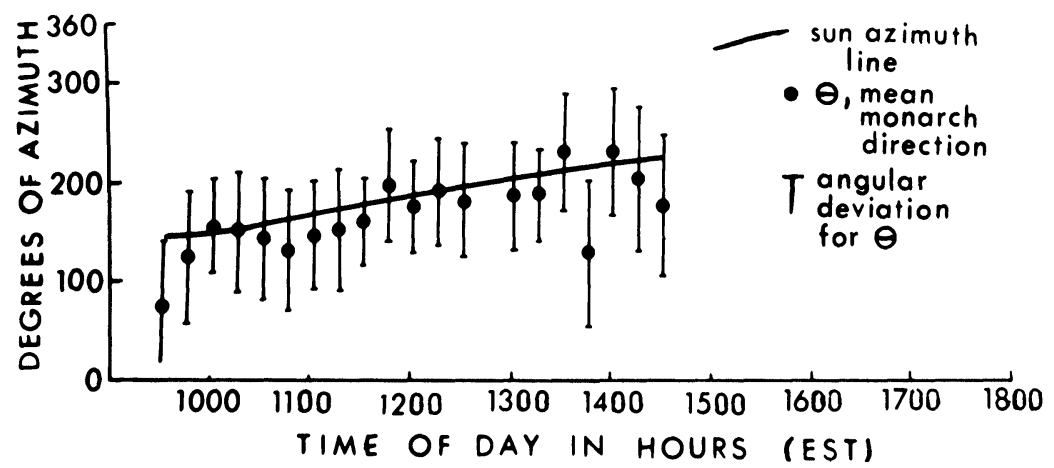

Fig. 3. Orientation of fall migrants captured in the field and tested in opaque periphery orientation cages on a clear day. The orientation displayed by these migrants was a sun orientation.

The consistently random orientation of all Monarchs in no-sun tests, and the random orientation of summer non-migrants reared under a photoperiod advanced 6 hours and tested on no-sun days (Table I), argue against a time-compensating, sun-compass orientation in experiments with opaque periphery cages. von Frisch (1967) showed that a patch of blue sky subtending an angle of only $10^{\circ}$ to $15^{\circ}$ was not only sufficient for the honeybee to localize the sun's position, but also that the honeybee was capable of a sun-compass orientation using polarized light. The sun's position can be uniquely described for most times of the day by the pattern of polarized light (Stockhammer, 1959; von Frisch, 1967). Experiments with summer laboratory-reared non-migrants and fall Monarchs suggested that the sun orientation of these animals was dependent on the sun being directly visible. On partly cloudy days, opaque periphery cage non-migrants and fall migrants oriented randomly when the sun was obscured by clouds but sun-oriented when the sun was not obscured by clouds. Summer non-migrants (laboratory-reared) and fall migrants, in opaque cages with a sun-shade blocking the sun but the remainder of the sky visible, showed a random orientation with the shade in place and a sun orientation when it was removed (Table I).

\section{Orientation in Transparent Periphery Cages}

Tests performed with transparent periphery orientation cages exposed Monarchs to terrestrial as well as celestial orientation cues. 


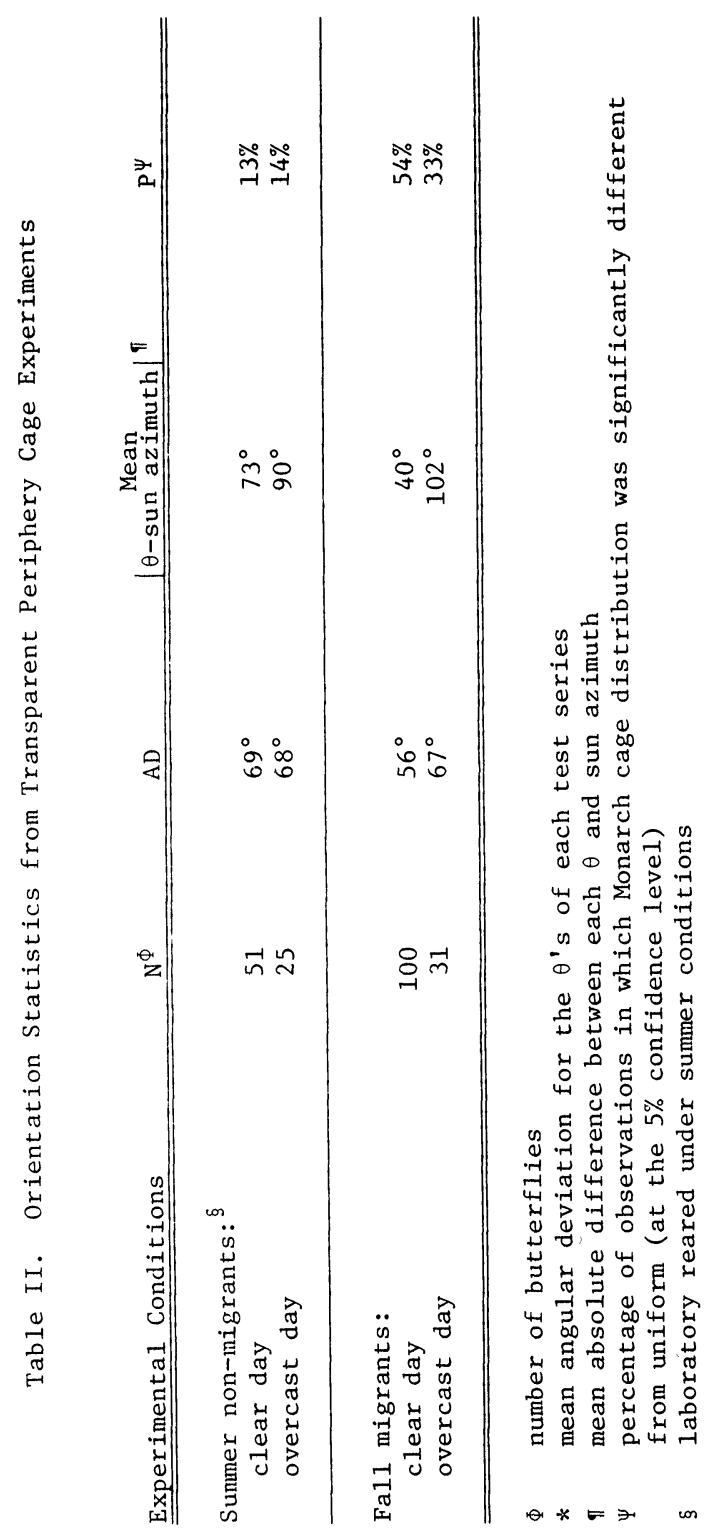


The orientation of summer laboratory-reared, non-migrant Monarchs in transparent periphery cages was random with or without the sun visible (Table II), and was comparable to the random orientation shown by opaque periphery cage non-migrants and migrants in the absence of sun cues. Therefore, the presence of terrestrial cues over-rides the sun-orienting escape response of non-migrant Monarchs. It is possible that using terrestrial instead of sun cues each non-migrant butterfly persisted in its orientation cue for escape. These experiments demonstrate that the majority of non-migrant Monarchs chose terrestrial rather than sun cues for orientation when both were available.

Fall migrants, exposed to both terrestrial and sun cues, continued to orient to the sun's azimuth (Fig. 4, Table II) with an orientation closer to the sun's azimuth from 1000-1400 hrs, EST, than either before or after this period $\left(\mid \theta\right.$-sun azimuth $\mid$ value being $35^{\circ}, 52^{\circ}$ and $77^{\circ}$, respectively). An exception was seen in one sun-visible test, in which $\theta$ 's from most significantly grouped animals maintained an approximately $240^{\circ}$ heading (southwest). However, this occurred only once and one cannot determine whether terrestrial or celestial cues were used. Random orientation resulted with terrestrial cues present but sun clues absent (Table II). The persistent sun orientation of fall migrants, when the sun and terrestrial cues were visible, is additional support for the hypothesis that the sun orientation of fall migrants is a migratory response and not merely an escape response.

\section{Flight Directions Following Release}

Monarchs were released after each experiment and an azimuth reading taken on the vanishing direction of each butterfly using a Silva compass compensated for declination angle. Only those butterflies that flew to the horizon were used in the analysis of Monarch vanishing directions. All Monarchs exhibited speed flight (Urquhart, 1960) immediately upon release. Occasionally Monarchs showed a feeding flight pattern with short randomly directional flights between flowers. When feeding flight took a butterfly to the horizon of the test field within 2 minutes, its azimuth at the periphery was included in the analysis; if feeding flight persisted, the vanishing azimuths of such animals were excluded from computations. Flight altitudes of released Monarchs were evenly divided between those above and below approximately 8 meters. 


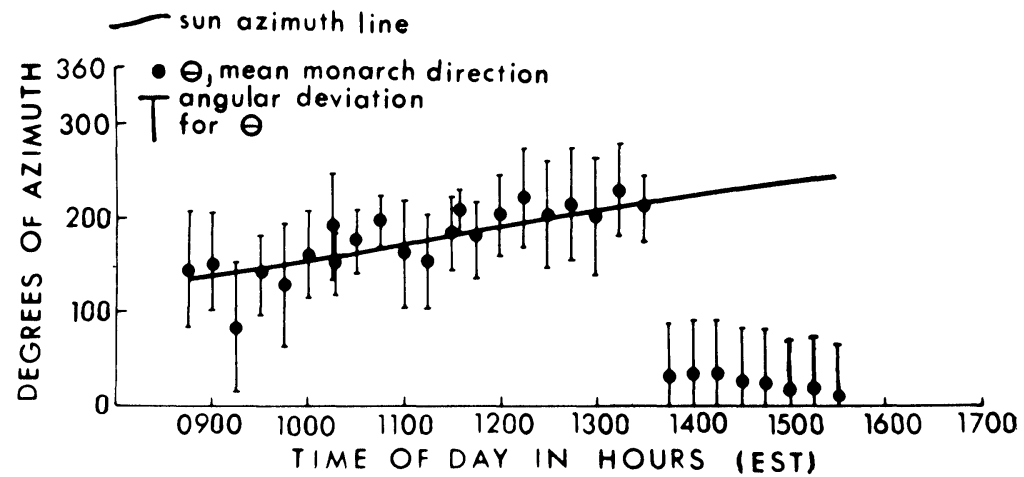

Fig. 4. Orientation displayed by fall migrants in a transparent periphery cage on a clear day. In contrast to summer non-migrants, fall migrants continue to sun-orient in the presence of both sun and terrestrial cues. Readings beginning at $1345 \mathrm{hrs}$ (EST) were an artifact of a sudden ambient temperature drop.

The results of summer Monarch releases with the sun visible showed that most vanishing azimuths appeared to be down-wind rather than toward the sun (Fig. 5). Only the releases of (c), (f) and $(h)$ were significantly grouped about their respective mean orientation direction. Vanishing azimuths for summer non-migrants on overcast days were down-wind (Fig. 6). The distribution of releases in all but (c) were significant about their respective $\theta$ 's. The releases of (f), with only a light surface wind, appear to be in the direction of the sun's azimuth even though the sun's position was obscured by clouds. However, most of these butterflies flew at an altitude $\geqslant 20 \mathrm{~m}$ and, therefore, likely encountered stronger winds. The vanishing directions of summer Monarchs, therefore, appeared more influenced by wind than by sun. Vanishing azimuths were more scattered with light winds ( $\leqslant 5 \mathrm{mph}$ or $8 \mathrm{~km} / \mathrm{hr}$ ). Low flight enabled Monarchs to fly against head winds that exceeded $10 \mathrm{mph}(16 \mathrm{~km} / \mathrm{hr})$. Thus, Monarch flight direction was greatly influenced by the wind but was not competely determined by wind direction.

Figure 7 shows the patterns of vanishing azimuths for fall migrants when the sun was visible. All 20 distributions were significant about their respective $\theta$ 's. The vanishing azimuths generally corresponded to the direction in which the wind was blowing with the exception of $(a),(m)$ and $(t)$. The releases of (a) occurred from a site that was surrounded by water except to the west; Urquhart 


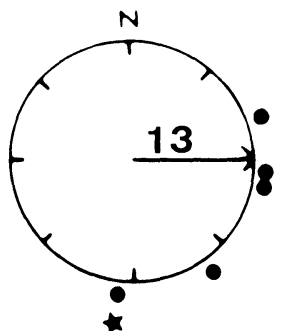

a
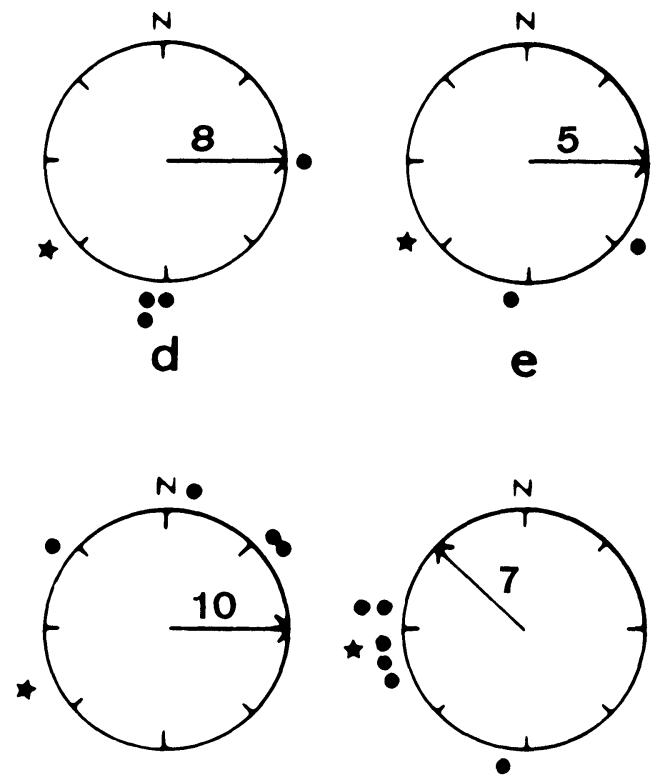

h

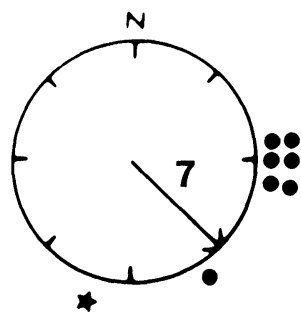

C

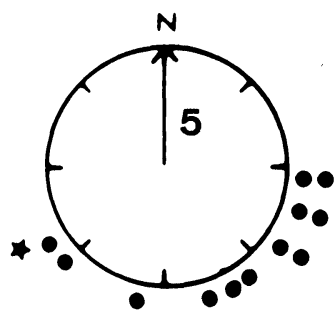

f

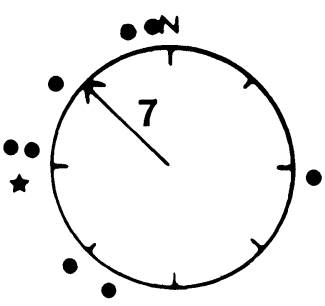

i

Fig. 5. Release orientation for summer monarchs on clear days. For each circle: Dot indicates the vanishing direction of a butterfly; star indicates sun position at the time of release; radial arrow indicates direction in which wind was blowing and its velocity in miles per hour; $\mathrm{N}$ indicates true north. Most vanishing azimuths are seen to be down-wind. 


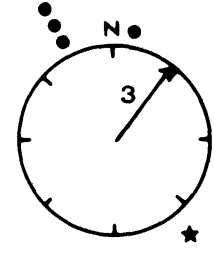

a

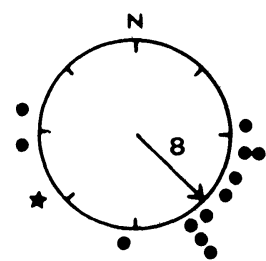

d

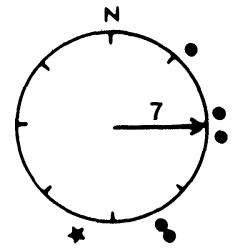

b

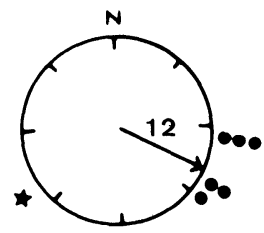

e

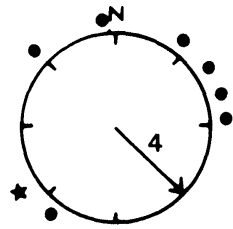

C

Fig. 6. Release orientation for summer monarchs on overcast days. Symbols are as in Fig. 5. Most vanishing directions were down-wind.

(1960) has observed that Monarchs tend to avoid flying over water when possible. Most flights in $(\mathrm{m})$ were low to the ground, as was true for the majority of flights showing vanishing azimuth into the wind. The releases of (t) occurred at $1600 \mathrm{hrs}$ (EST) when migrants return to roosting trees for the night. The roosting trees for migrants at Gloucester were west and northwest of the release and feeding sites. Thus, the migrants of $(t)$ were possibly returning to their roosting trees; however, it is unclear why the butterflies in (c) chose a similar direction at $1300 \mathrm{hrs}$ (EST) with the same wind velocity as in $(\mathrm{t})$.

Vanishing directions appeared to be down-wind, particularly when winds exceeded $10 \mathrm{mph}(16 \mathrm{~km} / \mathrm{hr})$ unless the butterfly flew low to the ground. Two-way analysis of variance between the mean angular deviation of $22^{\circ}$ for (h), (i), (k), (l), (n) and (o) and the mean angular deviation of $42^{\circ}$ for the remaining fourteen release distributions indicate significant differences $(\mathrm{F}=9.5 \mathrm{df}=16, P<$ $.01)$. In the former case, the wind was blowing in the same direction (southwest) as the sun's azimuth. In the latter case, the wind and sun azimuth directions did not coincide. Analysis of variance of 


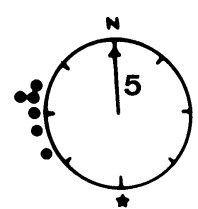

a

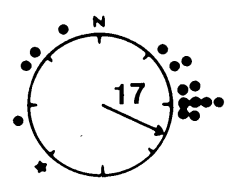

e
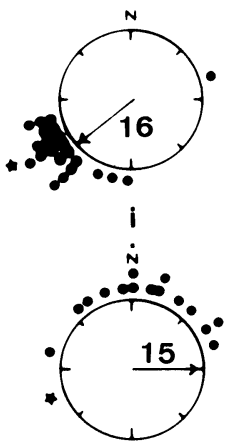

m

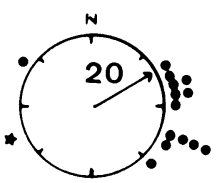

$\mathbf{q}$

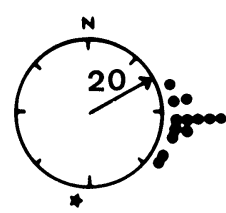

b

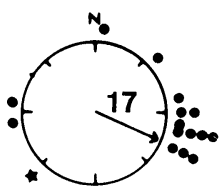

f

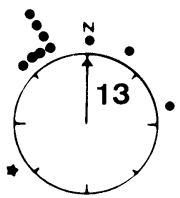

$\mathbf{j}$

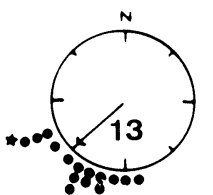

n

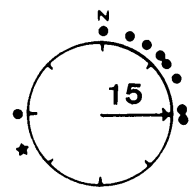

$\mathbf{r}$

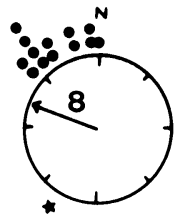

C

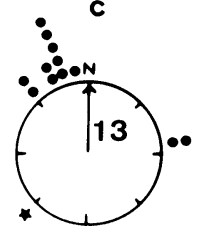

$\mathbf{g}$
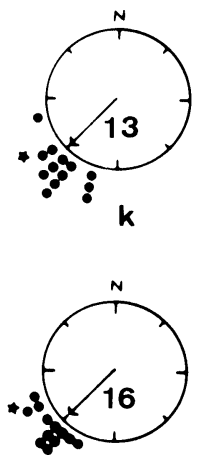

o

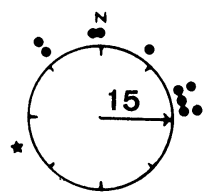

$\mathbf{s}$
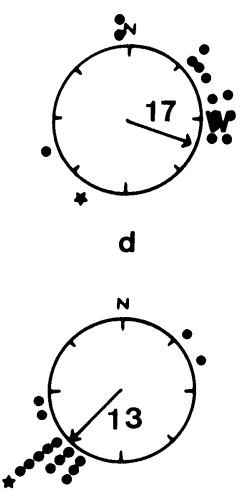

h
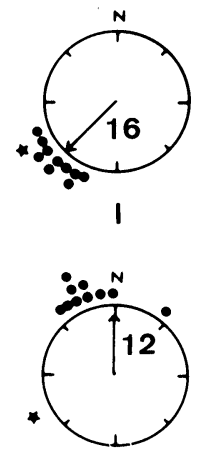

$\mathbf{p}$

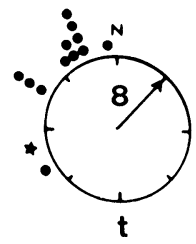

Fig. 7. Vanishing directions of fall migrants on clear days. Symbols are as in Fig. 5. Most releases flew down-wind but distributions for north and northeast winds are tighter than those for southerly winds. See text for discussion. 

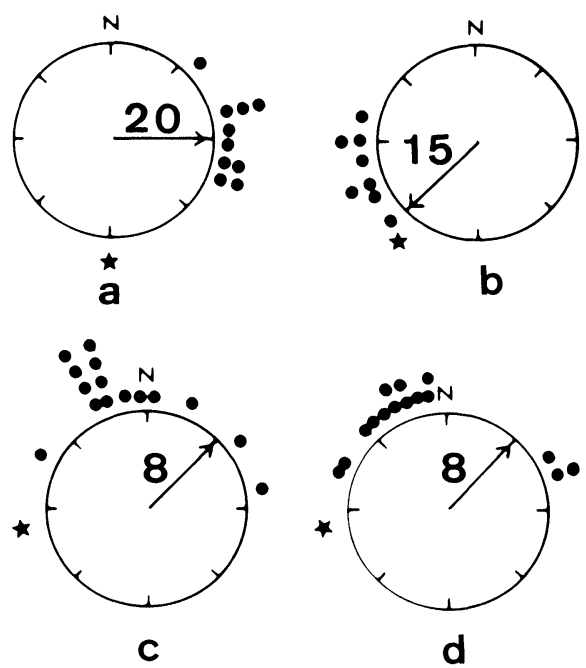

Fig. 8. Vanishing directions for fall migrants released on overcast days. Symbols are the same as in Fig. 5. Monarchs flew generally down-wind.

angular deviations for winds of $13 \mathrm{mph}(21 \mathrm{~km} / \mathrm{hr})$ shows that the mean $\mathrm{AD}$ of $17^{\circ}$ for distributions (h), (k) and (n) with the sun and wind in the same direction was significantly smaller than the mean $\mathrm{AD}$ of $28^{\circ}$ for distributions $(\mathrm{g}),(\mathrm{j})$ and $(\mathrm{p})$ with sun and wind directions dissimilar $(\mathrm{F}=4.9, \mathrm{df}=5, P<.1)$. The same was true for winds of $16 \mathrm{mph}(26 \mathrm{~km} / \mathrm{hr})$ where the mean $\mathrm{AD}\left(18^{\circ}\right)$ for (i), (l) and (o) with sun and wind to the southwest was significantly smaller than the mean $\operatorname{AD~}\left(46^{\circ}\right)$ for (d), (e), (f), (m), (r) and (s) with the sun and wind directions dissimilar $(\mathrm{F}=30.8, \mathrm{df}=8, P<0.005)$. Therefore, these data suggest that fall migrants were not just flying with prevailing winds but were also orienting toward the sun.

The vanishing azimuths for fall migrants released on overcast days were predominantly down-wind and each distribution was significant about its $\theta$ (Fig. 8). Releases (c) and (d) occurred at $1630 \mathrm{hrs}$ and $1700 \mathrm{hrs}$ (EST), respectively, and could be examples of the roosting orientation described for Fig. $7(t)$.

Thus, although the sun is an important cue in oriented flight, fall migrants utilize favorable winds to facilitate migration, but display oriented flight without the aid of the wind. 


\section{DISCUSSION}

The experiments reported here were designed to delineate the role of the sun in Monarch orientation. The sun was selected as the most probable cue in the orientation of Monarch butterflies for several reasons: (1) the Monarch is a diurnal animal and the sun is a prominent cue in its environment; (2) a positive phototaxis has been reported in a number of Lepidoptera (Brandt, 1934; Collins, 1935; Dolley, 1916; Jander, 1963; and Kelsheimer, 1935); (3) the sun has been shown to be important in the orientation of a number of animals (Hasler, 1967; Schmidt-Koenig, 1961; Taylor and Ferguson, 1969; and von Frisch, 1967), including migrating European butterflies (Baker, 1968a,b).

Non-migrant Monarchs (laboratory-reared) demonstrated a sun orientation when tested in an opaque periphery orientation cage with the sun visible. This response was termed an escape response. A sun-orienting escape response for Monarch butterflies is appropriate for three reasons. First, the most prominent orientation cue available to Monarchs in opaque periphery cages on a clear day is the sun. Second, when fast escape flight is warranted, Monarch escape would be linear and, therefore, fastest when the animals use a constant cue, such as the sun, for orientation. Third, when followed by a predator, a sunward escape response would put the sun in the predator's line of sight thus making it more difficult for the Monarch to be detected.

The orientation of summer non-migrants was random with both terrestrial and celestial cues present. If Monarchs were attempting to escape, the sun did not appear to be their orientation cue. This random orientation was believed to be indicative of the orientation of uncaged, non-migrant, Monarchs during the summer, since summer animals are known to wander randomly (Urquhart, 1960). Verheijen (1958) has criticized phototaxis experiments on the basis that the test situations eliminated scattered and reflected light, therefore making the illumination of the animal's environment unnatural. Illumination conditions (as well as conditions in general) during Monarch testing in transparent periphery cages, more closely approximated a natural field situation for Monarchs than the conditions encountered with opaque periphery cages. Thus the responses of transparent periphery cage butterflies might be expected 
to more accurately represent Monarch orientation.

It has been assumed that Lepidoptera displaying positive phototaxis (Johnson, 1969) were flying directly toward a light source. Hsiao (1973), however, has found that the corn earworm moth, Heliothis zea, flies toward a dark band surrounding the light source. Hsiao suggested that this Mach band explanation (Graham, 1966) could explain the attraction of night-flying moths to ultraviolet light sources: moths seek darkness characteristic of their diurnal behavior, although they appear attracted to ultraviolet light. Hsiao's results raise the possibility that sun orientation of Monarch butterflies is an orientation to either (1) a Mach band surrounding the sun, or (2) a Mach band perceived between the sun and the darker horizon. However, the Monarch is a diurnal butterfly, not a nocturnal moth, and butterflies generally seek sun-light areas instead of shaded areas (Klots, 1961).

Data from experiments with caged butterflies might represent landing orientation. However, when observations were made (at times ranging from 1-15 min after cage rotation), few, if any, Monarchs were in flight or landing. In general, the butterflies were either stationary or walking.

The location and shape of the horizon in opaque vs transparent periphery cages could also have affected Monarch orientation. Orientation to mountain tops by many Coccinellidae (Hagen, 1962), and to tree tops by the Scolytid beetle, Conophthorus coniperda (Henson, 1966), is presumably based on horizon-orientation. Nevertheless, sun orientation by fall migrant Monarchs persisted in spite of horizon differences between opaque and transparent periphery orientation cages. It seems unlikely, therefore, that the cage orientation of these insects was significantly affected by horizon differences. The orientation displayed by summer non-migrants was different in the two types of cages. This difference might reflect an horizon influence, but other factors, such as the presence or absence of terrestrial cues, are equally likely.

When the sun was visible, fall migrant Monarchs oriented to the sun's azimuth regardless of the type of orientation cage. In contrast, non-migrant orientation was sunward only in opaque periphery cages. One explanation for this difference in orientation response could be that a sun-orienting escape response is stronger in fall migrants than in summer non-migrants. Tables I and II show that the sun orientation of fall migrants (opaque or transparent 
periphery cages) was not as conclusive, statistically, as the sun orientation of summer non-migrants in opaque periphery cages. Furthermore, a stronger escape response could be expected to be positively correlated with a greater overall level of activity within a cage. It was found, however, that cage activity during fall tests was less than cage activity during summer tests.

The tendency of fall migrants to orient more closely to the sun's azimuth during the observed fall migratory period (1000-1400 hrs, EST) was another feature distinguishing fall migrant sun orientation from escape response sun orientation. A sun orientation restricted to the period 1000-1400 hrs would offer several advantages to Monarchs migrating south: (1) A restricted sun orientation encompasses an arc of $60^{\circ}$ to $70^{\circ}$ compared with an arc of $160^{\circ}$ to $180^{\circ}$ resulting from all-day sun orientation and the $60^{\circ}-70^{\circ}$ arc rarely deviates from the desired south to southwest migratory direction. (2) Consequently, the distance traveled, and time and energy expended, would be less. Tunmore (1960) has suggested a similar scheme for bird navigation. (3) A restricted sun orientation also obviates the necessity of sun-compass orientation to explain the precision of the Monarch's long-distance fall migration. The data suggest that the restricted sun orientation was independent of temperature (for ambient temperatures greater than $13^{\circ} \mathrm{C}$ ). (4) Since the highest autumn temperatures generally occur between $1000 \mathrm{hrs}$ and $1400 \mathrm{hrs}$ (EST), fall migrants would be migrating during the warmest part of the day.

If fall migrants use sun orientation, then spring migrants returning north might use a negative sun orientation. Reversed orientation by insects between leaving and returning to a site is well known (Geir, 1960; Johnson, 1969; Kennedy and Booth, 1963; Pickens, 1934; and Shephard, 1966).

Monarch migrations are undoubtedly affected by winds. However, while Monarch migrations appear to be aided by prevailing winds, they are not as dependent on them as locusts (Waloff, 1946, 1958) and aphids (Johnson, 1954, 1969). Figure 7 showed that the distributions of release azimuths were tighter when migratory and down-wind directions coincided than when the two directions differed. Furthermore, several instances were recorded (Kanz, 1973) where fall and spring migrants were engaged in directed migratory flights with little or no wind. The prevailing surface wind patterns for up to $500 \mathrm{~m}$ altitude (Prevailing Direction, Mean Speed and 
Fastest Mile of Wind, U.S. Weather Bureau) for September and October would facilitate a southwestward movement of Atlantic Coast migrants in the fall, and for March and April would facilitate a north and northeastward movement of migrants passing north through Mexico and Texas. Prevailing wind patterns for March and April suggest a possible explanation for why the population of Monarch butterflies in the United States (excluding the West Coast population) is proportionally greater east than west of the Mississippi River (Urquhart, personal communication). Strong March and April winds from the north, west, and northwest in northern Texas and Nebraska, could force spring Monarchs, orienting by a negative sun-orientation, to the east and northeast. Therefore, even a broad northerly orientation for spring migrants might still result in biasing the summer population toward the eastern half of the United States. Thus, it might not be necessary for Monarchs to possess a restricted negative sun orientation in order to assure a northeasterly movement in the spring.

\section{SUMMARY}

Non-migrant and fall migrant male and female Monarch butterflies, Danaus plexippus L., orient toward the azimuth of the sun when confined in circular orientation cages with only celestial cues present. When both terrestrial and celestial cues are present, nonmigrants exhibit random directionality similar to the flight of freeflying summer non-migrants while fall migrants orient to the sun's azimuth. Both fall migrants and non-migrants exhibit a random cage distribution under overcast sky with or without terrestrial cues. The sun orientation of fall migrants is believed to be a migratory response resulting in a southward movement. Such orientation differed from the sun orientation of non-migrants which appears to be an escape response. Upon release, migrants and non-migrants tend to fly with the wind. No conclusive indication of sun-compass or polarized light orientation in migrants or nonmigrants was evident. No sex differences in orientational responses were observed.

\section{ACKNOWLEDGMENTS}

I wish to thank Dr. E. S. Hodgson for his advice and support during this study. In addition, I am indebted to Dr. F. A. Urquhart of the University of Toronto and Dr. L. P. Brower of Amherst 
College for their help in establishing a laboratory colony of Monarch butterflies. I would also like to thank Ms. Mary Kanz for her assistance throughout the field studies. This research was supported, in part, by funds derived from an NIH Career Development Award to Dr. K. D. Roeder, Tufts University.

\section{REFERENCES}

BAKER, R. R. (1968a). A possible method of evolution of the migratory habit in butterflies. Phil. Trans. R. Soc. (B), 253, 309-341.

BAKER, R. R. (1968b). Sun orientation during migration in some British butterflies. Proc. R. ent. Soc. (A), 43, 89-95.

BAtschelet, E. (1965). Statistical methods for the analysis of problems in animal orientation and certain biological rhythms. AIBS Monograph, Washington, D.C.

BRANDT, H. (1934). Die Lichtorientierung der Mehlmottle Ephestia Kuehniella Zeller. Z. vergl. Physiol., 20, 646-673.

Collins, D. L. (1935). Comments upon phototropism in the codling moth with reference to the physiology of the compound eyes. J. econ. Ent., 28, 103-106.

Dolley, W. L. (1916). Reactions to light in Vanessa antiopa, special reference to circus movements. J. exp. Zool., 20, 357-420.

GeIR, P. W. (1960). Physiological age of codling moth females (Cydia pomonella (L)) caught in bait and light traps. Nature, Lond., 185, 709.

Graham, C. H. (1966). Vision and Visual Perception. New York: John Wiley and Sons.

Greenwood, J. \& Durand, D. (1955). The distribution of length and components of the sum of n random unit vectors. Ann. math. Statist., 26, 233-246.

Hagen, K. S. (1962). Biology and ecology of predaceous Coccinellidae. A. Rev. Ent., 7, 289-326.

Hasler, A. (1967). Underwater guideposts for migrating fishes. In: Animal Orientation and Navigation, pp. 1-20. Corvallis, Oregon: Oregon State University Press.

Henson, W. R. (1966). The analysis of dispersal mechanisms in Conophthorus coniperda Sz. Biometeorology 2. Proc. III Int. Congr. Biomet. (Pau, 1963), pp. 541-549.

HsıaO, H. S. (1973). Flight paths of night-flying moths to light. J. Insect. Physiol., 19, 1971-1976.

JANDER, R. (1963). Insect Orientation. A. Rev. Ent., 8, 95-114.

Johnson, C. G. (1954). Aphid migration in relation to weather. Biol. Rev., 29, 87-118.

Johnson, C. G. (1969). Migration and Dispersal of Insects by Flight. London: Methenun and Co., Ltd.

KAMMER, A. E. (1968). Motor patterns during flight and warm-up in Lepidoptera. J. exp. Biol., 48, 89-109.

Kammer, A. E. (1970). Thoracic temperature, shivering, and flight in the monarch butterfly Danaus plexippus (L). Z. vergl. Physiol., 68, 334-344. 
KANZ, J. E. (1973). The orientation of non-migrant and migrant monarch butterflies (Danaus plexippus). Ph.D. Dissertation. Medford, Massachusetts: Tufts University.

Kelsheimer, E. G. (1935). Response of European corn borer moths to colored lights. Ohio J. Sci., 35, 17-28.

Kennedy, J. S. \& Booth, C. O. (1963). Free flight of aphids in the laboratory. J. exp. Biol., 40, 67-85.

KLots, A. B. (1951). A Field Guide to the Butterflies. Boston: Houghton Mifflin Co. (The Riverside Press).

Nielsen, A. \& Nielsen, E. T. (1952). Migration of the pieride butterfly Ascia monuste L. in Florida. Ent. Meddr., 26, 386-391.

Pickens, A. L. (1934). Termites and Termite Control (Ed. by C. A. Kofoid). Los Angeles: University of California Press.

Prevailing Direction, Mean Speed, and Fastest Mile of Wind; from National Atlas of the United States. U.S. Weather Bureau, U.S. Department of Commerce, Washington, D.C.

Schmidt-Koenig, K. (1961). Sun navigation in birds? Nature, Lond., 190, 10251026.

SHEPHARD, R. F. (1966). Factors influencing the orientation and rates of acitivity of Dendroctonus ponderosae Hopkins (Coleoptera: Scolytidae). Can. Ent., 98, 507-518.

Stockнамmer, K. (1959). Die Orientierung nach der Schwingungsrichtunglinear polarisierten Lichtes und ihre sinnesphysiologischen Grundlagen. Ergebn. Biol., 21, 23-56. Summarized in: The Dance Language and Orientation of Bees by Karl von Frisch (1967). Cambridge, Mass.: Harvard University Press.

Tables of Computed Altitude and Azimuth, Latitudes $40^{\circ}-49^{\circ}$ N. Inclusive (1962). U.S. Navy Hydrographic Office, Publication No. 214, Volume V. Washington, D.C.: U.S. Government Printing Office.

Taylor, D. H. \& Ferguson, D. E. (1969). Solar cues and shoreline learning in the Southern Cricket Frog, Acris gryllus. Herpetologica, 25, 147-149.

The National Almanac, for Years 1970-1973. Issued by the U.S. Naval Observatory. Washington, D.C.: U.S. Government Printing Office.

TILDEN, J. W. (1962). General characteristics of the movement of Vanessa cardui (L). J. Res. Lepidop., 1, 43-49.

Tunmore, B. G. (1960). A contribution to the theory of bird navigation. Proc. XII Int. Ornith. Cong., Helsinki, pp. 718-723.

Urquhart, F. A. (1960). The Monarch Butterfly. Toronto, Canada: University of Toronto Press.

Urquhart, F. A. (1976). Found at last: The Monarch's winter home. National Geographic, 150 (12): 161-173.

Urquhart, F. A. \& Stegner, R. W. (1966). Laboratory techniques for maintaining cultures of the monarch butterfly. J Res. Lepidop., 5, 129-136.

VERHEIJEN, F. J. (1958). The mechanisms of the trapping effect of artificial light sources upon animals. Archs. neerl. Zool., 13, 1-107.

von Frisch, K. (1967). The Dance Language and Orientation of Bees. Cambridge, Mass.: Harvard University Press. 
Walker, J. J. (1914). The geographical distribution of Danaida plexippus L. (Danais archippus $\mathrm{F}$.) with especial reference to its recent migration. Entomologist's mon. Mag., 50, 181-193, 224-237.

WALOFF, Z. (1946). A long-range migration of the Desert Locust from Southern Morocco to Portugal, with an analysis of concurrent weather conditions. Proc. R. ent. Soc. (A), 21, 81-84.

Waloff, Z. (1958). The behaviour of locusts in migrating swarms. Proc. $X$ Int. Congr. Ent., Montreal, 2, 567-570.

Williams, C. B. (1951). Seasonal changes in flight direction of migrant butterflies in the British Isles. J. Anim. Ecol., 20, 180-190.

Williams, C. B. (1958). Insect Migration. London: Collins Press.

Williams, C. B., G. F. Cockbill, M. E. GibBs, J. A. Downes (1942). Studies in the migrations of Lepidoptera. Trans. R. ent. Soc., Lond., 92, 101-283. 

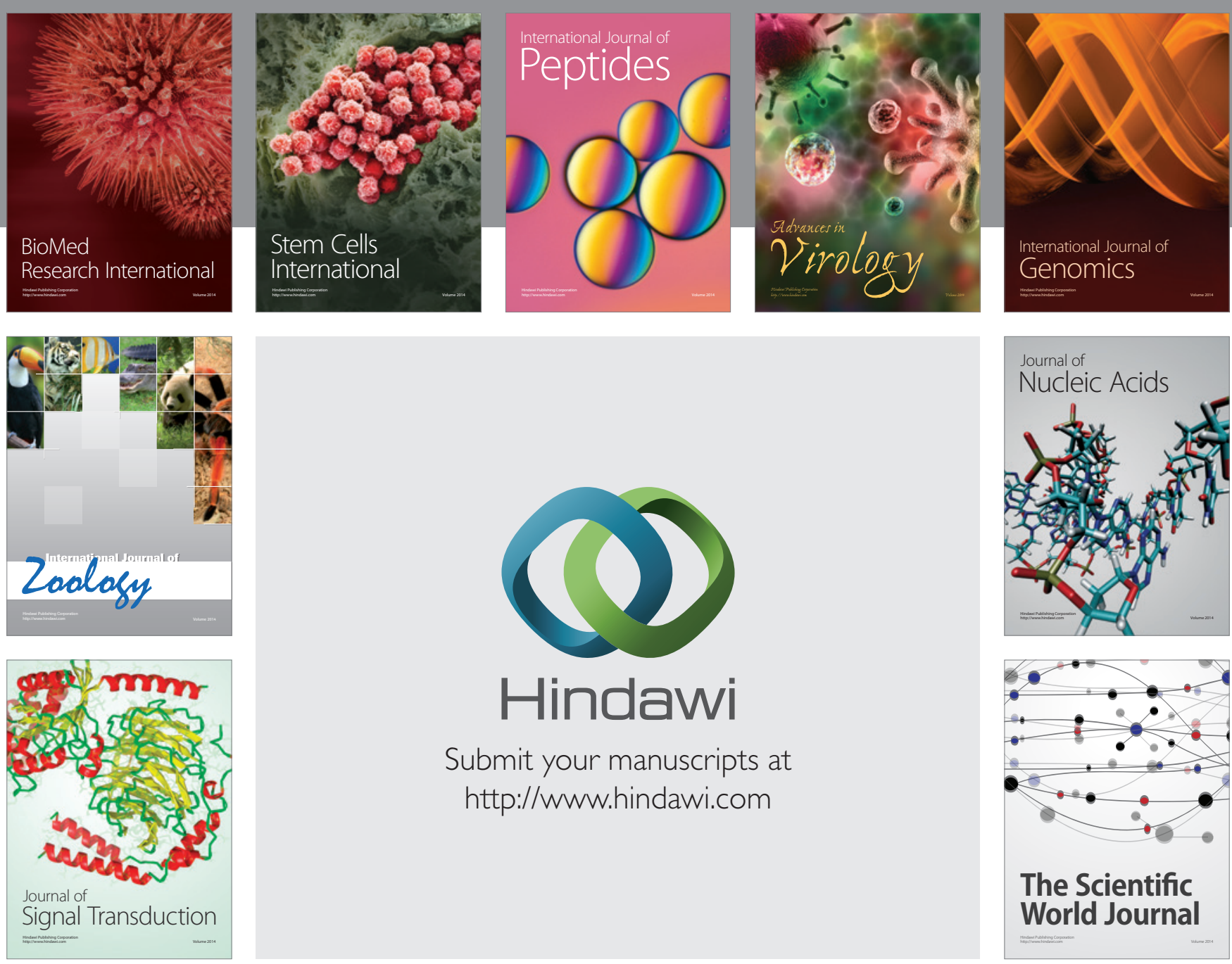

Submit your manuscripts at

http://www.hindawi.com
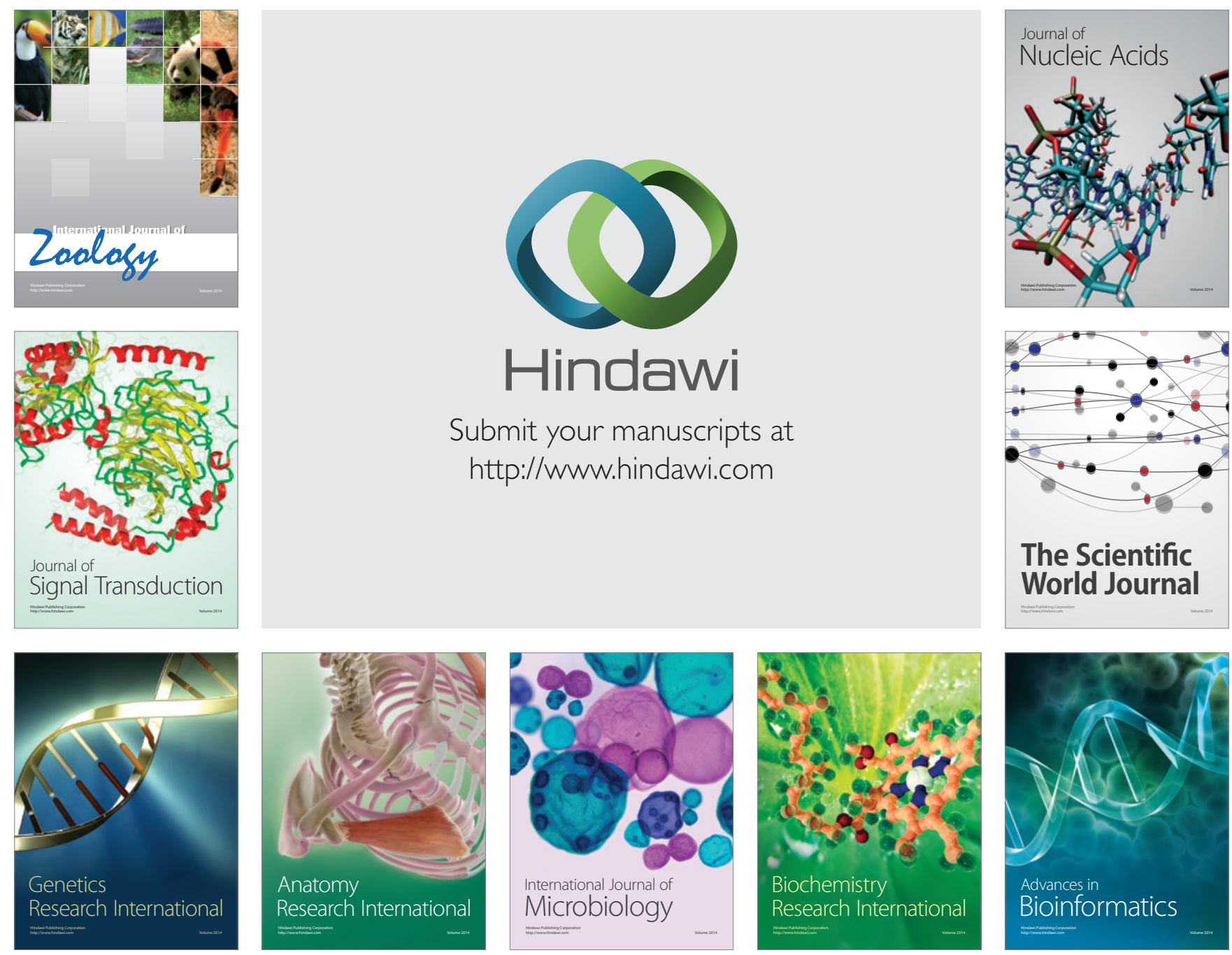

The Scientific World Journal
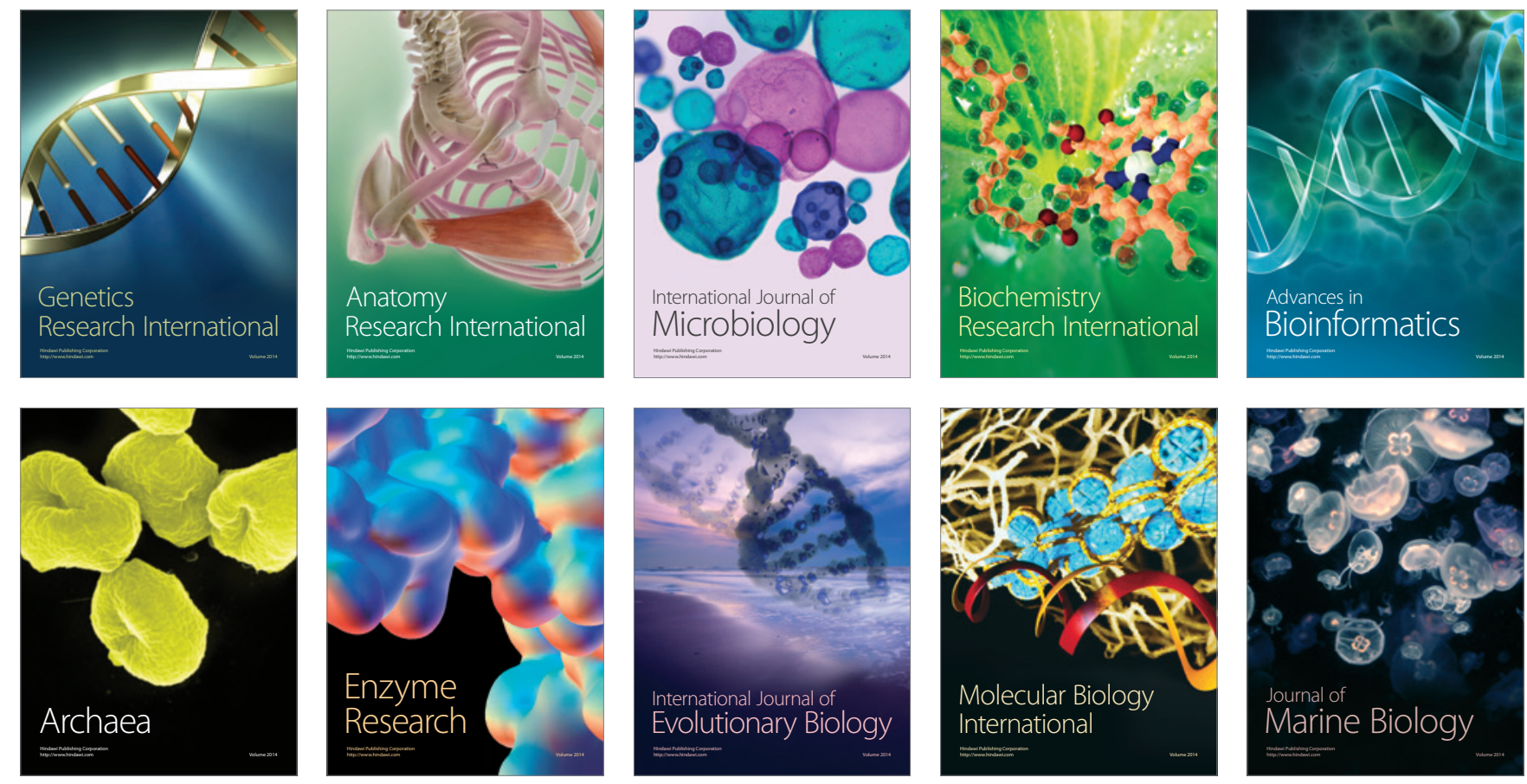